\title{
Predictors of Physical Activity on a College Campus with a High Proportion of Non-traditional Students
}

\author{
Ka Man Leung ${ }^{1}$, Lynda B. Ransdell ${ }^{2}$, Yong Gao ${ }^{3}$, Jane Shimon ${ }^{3}$, Shelley Lucas ${ }^{3}$, and Pak- \\ Kwong Chung ${ }^{1}$ \\ ${ }^{1}$ Department of Physical Education, Hong Kong Baptist University, Kowloon Tong \\ ${ }^{2}$ School of Nutrition and Health Promotion, Arizona State University \\ ${ }^{3}$ Department of Kinesiology, Boise State University
}

\begin{abstract}
Background and purpose: Given the problem of obesity, physical inactivity and sedentary lifestyles among college students in the US, this study presents demographic, psychosocial, personal and environmental predictors of physical activity (PA) on an individual college campus with a high percentage of non-traditional students. Methods: The National College Health Assessment (NCHA) survey was completed by college students at a large Northwestern university $[\mathrm{N}=949$; Male $=292$ $(31.1 \%)$; female $=647(68.9 \%)$; mean age $=26.5(\mathrm{SD}=9.0)$ years $]$ during Fall 2011. Results: Sixty-eight percent of participants did not meet both moderate to vigorous physical activity (MVPA) and strength exercise (SE) recommendations. Good perceived health status and on-campus housing status were associated with a higher probability of meeting the MVPA and SE recommendations $(p<.05)$, with the former also predictive of SE. High Interest in PA, high PA knowledge, low stress, male gender and young age explained additional variance in meeting the SE recommendation $(p<.05)$. Conclusion: Most students did not participate in the recommended level of MVPA and SE. On this campus, efforts directed to increasing PA knowledge might facilitate an increase in SE. Efforts to promote exercise as a stress reliever may also increase SE participation.
\end{abstract}

(c) 2016 Californian Journal of Health Promotion. All rights reserved.

Keywords: determinants, university population, exercise, recommendation

\section{Introduction}

Physical Activity (PA) is an important health behavior that is often established early in life (Craigie, Lake, Kelly, Adamson, \& Mathers, 2011). Increasing PA in college students is so important, that it was listed as one of six priorities in the Healthy Campus 2010 document [American College Health Association (ACHA), 2002]. One way that colleges and universities can more effectively plan and implement PA interventions on campus is to use data to drive their planned PA interventions (ACHA, 2012). Data-informed interventions is a strategy that has been successfully used to address a variety of college student health behaviors including selection of fruit in campus dining halls (Reed, Powers, Greenwood, Smoth, \& Underwood,
2011), and enhancing sleep quality (Asano et al., 2015).

\section{Predictors of Physical Activity in College Students}

Researchers have examined demographic, psychosocial, personal and environmental predictors of PA among college students (Keating, Guan, Piñero, \& Bridges, 2005). Variables such as age, gender, and ethnicity have been suggested as reliable predictors of PA on college campuses (Buckworth \& Nigg, 2004; Fountaine, Liguori, Mozumdar, \& Schuna, 2011; Keating, Castelli, \& Ayers, 2013; McArthur \& Raedeke, 2009). Older students (i.e., age above 30 years), Asian-Americans and African Americans tend to be less active than their counterparts. Gender is an inconsistent predictor of PA in college students, as some researchers 
maintain that gender differences are less prevalent in college students, and others have suggested that males engage in more vigorous activities more than their female counterparts (Keating et al., 2005). Psychosocial factors such as social support from peers and friends (Gruber, 2008), high self-efficacy (Nehl et al., 2008) and perceived enjoyment or fun (Kilpatrick, Hebert, \& Bartholomew, 2005) have also been consistently linked to increased PA. Personal predictors of increased participation in PA include perceived health status as healthy (Lutz, Stults-Kolehmainen, \& Bartholomew, 2010), and knowledge about and interest in physical activity (Fielder, 2008). Environmental factors that predict increased levels of PA include close proximity to exercise facilities and higher perceived safety (Keating et al., 2005; Reed \& Phillips, 2005). While some trends appear relatively robust, many trends in these PA predictors are variable, and their importance or weight fluctuates by sample and/or college campus. In addition, the interaction of factors, unique to each college campus, may contribute to the type and level of PA on college campuses, and it may ultimately determine the success of any college-based PA interventions.

\section{Limitations in Current Literature}

Most previous studies have been conducted with traditional aged college students (i.e., age < 23 years) (Kulavic, Hultquist, \& McLester, 2013). Few have examined college campuses that serve a larger than average proportion of non-traditional aged students, who are typically older than 23 years, returning to school, commuting to campus, working full or part time, and supporting a family or juggling other adult responsibilities (Kulavic et al., 2013). Examining PA participation patterns in this population is important because the enrollment of non-traditional students is projected to increase from 7.9 million in 2010 to 9.7 million in 2019 across American universities (Snyder \& Dillow, 2011). According to the National Center for Education Statistics (Snyder \& Dillow, 2011), from 2010 to 2019, there will be a 9\% rise in enrollment of college students under 25, and a much larger 23\% rise in enrollment of college students 25 and older. Of those studies that have examined PA in non-traditional aged college students (NTS), Kulavic et al. (2013) found that NTS had different perceived PA barriers to and motivations for PA, compared to traditional college students. In addition, nontraditional aged college students were more motivated than their traditional aged counterparts to increase their PA due to perceived poor health and ill health avoidance, and they perceived more barriers to PA including fear of injury, lack of skill, and lack of resources. Quintiliani, Bishop, Greaney and Whiteley (2012) qualitatively analyzed predictors of PA among NTS in a university. The most robust predictors of PA included having support from a partner and/or family members, and having a flexible work environment that allowed time for PA participation.

While these studies have increased our understanding of PA predictors in college students, they had limitations including the use of convenience samples and the examination of only one type of PA, usually general PA, aerobic activity, or MVPA (Lowry et al., 2000). Keating, Castelli and Ayers (2013) examined the relationship between college students' participation in strength training and their academic performance, gender and ethnicity. Students who were either White or Latino, and had higher academic performance, reported higher levels of strength training. Rarely have multiple types of PA been examined in one study, using large scale data with a random sample. It is important to separate types of PA such as moderate-to-vigorous PA (MVPA) and strength training exercise (SE). This is because contemporary exercise prescriptions recommend participating in MVPA, strength training, and flexibility activities for positive health benefits (Garber et al., 2011). Also, research on PA predictors in college students is sparse compared to other health behaviors, and rarely have all types of predictors (i.e., demographic, psychosocial, personal and environmental) been examined concurrently; in addition, many of the PA measures used were not consistent across studies, and some instruments used lacked validity and reliability (Keating et al., 2005). 
Leung, K.M., Ransdell, L.B., Gao, Y., Shimon, J., Lucas, S., Chung, P. K. / Californian Journal of Health Promotion 2016, Volume 14, Issue 1, 44-56.

Given that the National College Health Assessment developed by ACHAis regularly administered on several American college campuses, and that the survey used and data collected are reliable and valid (ACHA, 2012), devising a methodology to examine PA on each campus, and identify campus-specific predictors of PA could help inform future PA interventions on campus (ACHA, 2012).

\section{Purpose}

The aim of this study was to conduct a secondary data analysis (using 2011 data from the NCHA II) to examine the predictors of recommended MVPA and SE participation on a large urban campus in the Northwest that serves a larger than average proportion of nontraditional aged students. The NCHA II contains questions about college student participation in MVPA and SE, and questions about specific variables that have previously predicted participation in PA including: (a) demographic variables (i.e., age, gender, ethnicity, housing status, body mass index, academic performance and type of student), (b) psychosocial/personal variables (i.e., perceived health status, knowledge about PA, interest in receiving information about PA), and (c) environmental variables (i.e., perceived safety, stress). We hypothesized that demographic (i.e., age, gender, ethnicity, housing status, body mass index, academic performance and type of student), psychosocial〉personal (i.e., perceived health status, knowledge about PA, interest in receiving information about $\mathrm{PA}$ ), and environmental predictors (i.e., perceived safety, stress) will significantly associate with the probability of meeting MVPA and SE recommendations. If the factors related to PA participation in non-traditional aged college students are known, this university will be better positioned to design interventions that will increase physical activity and improve the health and well-being of its students. For instance, Chappell (2011) successfully utilized NCHA data to develop a multidimensional "Healthful Living Residential Interest Group program” and aimed to intervene on students' exercise and nutrition habits, and physical fitness. The intervention exhibited a positive impact in students' PA participation.

\section{Methods}

\section{Study Design and Participants}

The study was approved by the Institutional Review Board (IRB) of the primary author's affiliation and was conducted during the Fall of 2011 at a large, urban university in the Northwestern United States. A random webbased survey, using procedures recommended by the ACHA, was used to collect data. Undergraduate and graduate students enrolled in four or more credits during the fall 2011 semester $(n=4,500)$ were invited to participate via an e-mail message. The students completed the survey by clicking a link to the survey, and completion took approximately 20-30 minutes. Two reminder emails were sent over the course of the study in October 2011. Participation in this study was voluntary, and all students provided informed consent. In the studied university, about $89 \%$ of graduate students and $37 \%$ of undergraduate students were nontraditional aged (i.e., 25 years of age or older). The average age of undergraduate students at this university was 25.96 years; thus this study provides a model for examining PA on an urban campus serving a population that consists of a proportionally large number of NTS.

A total of 949/4,500 students (mean age $=26.5$ years, SD $=9.0$ ) completed the online survey (21\% response rate). Among participants (mean age $=26.5$ years, $\mathrm{SD}=9.0$ ), $55 \%$ of them were NTS aged 25 years or above.

\section{Measures}

National College Health Assessment. Developed by the ACHA, the NCHA II is a 66item assessment, covering different health topics (e.g., PA and nutrition) among college students in the United States. Concurrent validity has been established based on comparisons with other national databases such as National College Health Risk Behavior Survey, and reliability has been repeatedly established (ACHA, 2012). A subset of items from this assessment was used in the current study. These items were selected based on previous evidence suggesting that the concepts were significant predictors of PA in college students. For each of the variables included in the regression equation 
(described below), a factor score was computed and included as a predictor in the regression analyses.

Three items from the NCHA II assessed students' PA participation. Participants were asked about the number of days during the past 7-day period that they performed (a) moderate intensity cardiovascular or aerobic exercise for at least 30 minutes, (b) vigorous intensity cardiovascular or aerobic exercise for at least 20 minutes, and (c) 8-10 strength training exercises for 8-12 repetitions. Cronbach's alpha for the 3items on student's PA participation was .86 (ACHA, 2012).

MVPA was then re-coded as $1=$ "met recommendation" or $0=$ "did not meet recommendation" based on how many days they participated in at least 30 minutes of moderate PA or 20 minutes of vigorous PA (See (a) and (b) in the paragraph above), per the PA recommendations suggested by the American College of Sports Medicine and the American Heart Association (Haskell et al., 2007). SE was also re-coded as 1 or 0 , meaning the participants met or did not meet recommendations, based on whether they "performed one set of 8-10 strength exercises that condition the major muscle groups 2-3 days per week.”

Perceived health status was quantified using one item: "How would you describe your general health?" Responses to this question were recoded from six categories into two categories: 1 = "fair or poor health" (i.e., Fair and Poor) or 2 = "good or excellent health (i.e., Excellent, Very Good, and Good).”

Knowledge about PA was assessed by asking: "Have you received information on physical activity from your college or university?" Responses were scored using a dichotomous response item (i.e., Yes or No). Interest in receiving $P A$ information was assessed using another dichotomous response item: "Are you interested in receiving information on physical activity from your college and university?" Cronbach's alpha for knowledge about PA and interest in receiving PA information were .81 and .88 , respectively.
Four items were used to measure perceived safety: "How safe do you feel" during four conditions: on this campus (daytime and nighttime) and in the community surrounding this school (daytime and nighttime). A five-point Likert-type scale with a range from $1=$ "not safe at all" to 5 = "very safe" was used to gauge responses. Cronbach's alpha for perceived safety items was .74 (Babers-Henry, 2015).

Perceived stress was examined using three sets of items. The first set of 11 items asked the respondents to indicate how frequently they "felt overwhelmed" or "hopeless" during the past two weeks. The responses were $1=$ "No, never," to 5 $=$ "Yes, in the last 2 weeks." The next set of items measuring stress asked: "Within the last 12 months, have you been diagnosed or treated by a professional” for any of 15 listed mental health problems such as anorexia and insomnia. The responses were 1 = "Yes, diagnosed but not treated," to 5 = "Yes, other treatment." The last item asked respondents about their overall level of stress, with responses ranging from $1=$ "no stress" to $5=$ "tremendous stress." Cronbach's alpha for items related to stress ranged from .56 - .86 (ACHA, 2012).

Using all 27 items measuring student stress, six component factors were extracted, explaining $58.31 \%$ of the variance. The first factor, "perceived negative emotions" consisted of six items: feeling sad, feeling lonely, feeling hopeless, feeling so depressed it was difficult to function, feeling overwhelming anger, and feeling overwhelming anxiety. This factor accounted for $15.43 \%$ of the total variance in stress. The second factor, "compulsion," was related to compulsive behaviors such as binge eating and substance abuse. It consisted of seven items: being diagnosed and treated for schizophrenia, bulimia, substance abuse, anorexia, other addiction, phobia, and obsessivecompulsive disorder (OCD). This factor accounted for $11.59 \%$ of the variance in stress. The third factor, "diagnosis and treatment of mental illness" explained $10.60 \%$ of variance in stress. This factor was assessed using six items: being diagnosed and treated for anxiety, panic attacks, depression, insomnia, other mental health conditions and sleep disorders. The fourth 
factor, "suicide," explained 7.74\% of variance. It consisted of three suicide related items: attempted suicide, seriously considered suicide and intentionally injured. The fifth factor, "overall stress," accounted for $7.13 \%$ of the variance in stress, and included three items: feeling overwhelmed, feeling exhausted and overall level of stress. The last factor, "diagnosis and treatment of impulsivity," explained 5.82\% of variance. It referred to the impulsive behaviors caused by attention deficit hyperactivity disorder (ADHD) and bipolar disorder (.e.g., inattentiveness, over-activity and the changing of good and irritable moods in a short period of time). The factor score coefficients of the above stress component factors were used as independent variables in further regression analysis for prediction of MVPA and SE recommendations.

Demographic characteristics. Demographic characteristics were examined including age, gender, ethnicity, housing status (e.g., on or off campus), body mass index [e.g., underweight/desired weight (BMI below 24.9 $\mathrm{kg} \mathrm{m}^{-2}$ ) and overweight/obese (BMI above 25 $\left.\mathrm{kg}^{-2}\right)$ ], academic performance by cumulative grade point average (A, B, C or below) and type of student (e.g., U.S. or international student).

\section{Analyses}

Data analyses were conducted using SPSS (Version 19.0) with significance level set at .05. Two separate stepwise logistic regression analyses were conducted to determine the significant predictors for the dichotomous outcome variables (i.e., meeting or not meeting the MVPA or SE recommendations, respectively). The studied predictor variables included (a) demographic variables (i.e., age, gender, ethnicity (i.e., white and other), housing status, body mass index, academic performance and type of student), (b) psychosocial/personal variables (i.e., perceived health status, knowledge about PA, interest in receiving information about PA), and (c) environmental variables (i.e., perceived safety, stress). Logistic regression was conducted with demographic variables, psychosocial/personal and environmental variables being entered in the first, second and third block, respectively in the regression analyses.

\section{Results}

The overall survey response rate was $21.3 \%$., which is comparable to that of other NCHA studies (ACHA, 2012). Table 1 presents demographic characteristics of the sample and details about which subgroups met the MVPA or SE recommendations. Most of the participants were undergraduate (88.9\%), White (85.1\%), and from the United States (94.2\%). The sample from this study accurately represents the Northwestern university campus studied in terms of age, ethnicity, and student status. Most of the students (mean age $=27.15$ years) in this university were undergraduate (85.6\%), White (80\%), and from the United States (95.5\%). A large proportion of the sample was female (68.9\%), lived off campus (73.3\%), was either overweight or obese (43.4\%), and did not meet the MVPA recommendation (68.1\%) or strength exercise recommendation (68.5\%).

\section{Predictors of Meeting MVPA and/or SE Recommendations}

Table 2 presents the results of the logistic regression analyses. Perceived health status $(\mathrm{p}=$ .03) was a significant predictor of meeting the MVPA recommendation. Students who reported "good or excellent health" were 2.19 times more likely to meet the MVPA recommendations compared to those who reported "poor health." Compared to students who lived on-campus, students who lived off-campus were only.60 times as likely to meet the MVPA recommendation $(\mathrm{p}=.02)$.

The predictors for meeting the SE recommendation include perceived health status $(\mathrm{p}=.01)$, knowledge about PA $(\mathrm{p}=.01)$, interest in receiving PA information $(\mathrm{p}=.02)$ and overall stress $(p=.01)$. Students who reported "good or excellent health" were 2.80 times more likely to meet the SE recommendations than those who reported "poor health"; students who had knowledge about PA and had interest in receiving information about PA were 1.66 and 1.50 times more likely to meet the SE 
Table 1.

Demographic Characteristics of the Sample, Stratified by MVPA or SE Recommendations.

\begin{tabular}{|c|c|c|c|c|c|c|}
\hline & $\mathrm{N}$ & $\%$ & Met MVPA recommendation & $X^{2}(\mathrm{p})$ & Met SE recommendation & $X^{2}(\mathrm{p})$ \\
\hline Overall & & & 302 (31.9\%) & & $293(31.5 \%)$ & \\
\hline \multicolumn{7}{|l|}{ Level of Education } \\
\hline Undergraduate & 833 & 88.9 & & & & \\
\hline Graduate & 91 & 9.7 & & & & \\
\hline Not Seeking Degree and Other & 13 & 1.4 & & & & \\
\hline Gender : Male/female & 292/647 & 31.1/68.9 & 95 (32.5\%)/ 202 (31.3\%) & $.03(.87)$ & $117(40.6 \%) / 172(27.1 \%)$ & 7.4(.01) \\
\hline Ethnicity: White /other & $799 / 140$ & $85.1 / 14.9$ & $255(32 \%) / 42(30 \%)$ & $1.43(.23)$ & $225(32 \%) / 39$ (28.7\%) & $2.05(.15)$ \\
\hline Housing & & & & $5.56(.06)$ & & 2.13(.35) \\
\hline On-campus & 139 & 14.7 & $64(46 \%)$ & & $51(37.2 \%)$ & \\
\hline Off-campus & 691 & 73.3 & $201(29.1 \%)$ & & 217 (32\%) & \\
\hline Other & 113 & 12 & 35 (31\%) & & $24(21.6 \%)$ & \\
\hline Body Mass Index & & & & $3.26(.07)$ & & $1.25(.26)$ \\
\hline Underweight/ Desired Weight & 524 & 56.6 & $193(36.9 \%)$ & & $177(34.2 \%)$ & \\
\hline Overweight/ obese & 401 & 43.4 & $104(25.9 \%)$ & & $109(27.7 \%)$ & \\
\hline Academic Performance & & & & $1.08(.58)$ & & $4.90(.09)$ \\
\hline Cumulative GPA: A & 336 & 35.8 & $109(32.4 \%)$ & & 105 (31.7\%) & \\
\hline Cumulative GPA: B & 443 & 47.2 & $136(30.8 \%)$ & & $127(29.2 \%)$ & \\
\hline Cumulative GPA: C or Below & 160 & 17 & $52(32.5 \%)$ & & $57(36.3 \%)$ & \\
\hline Type of student: International/ U.S. & $54 / 881$ & $5.8 / 94.2$ & $14(25.9 \%) / 283(32.2 \%)$ & $1.65(.20)$ & $12(23.1 \%) / 277$ (31.9\%) & 4.67(.03) \\
\hline
\end{tabular}


recommendation, respectively. Compared to students who had lower overall stress, students experiencing high levels of stress were only .81 times as likely to meet the SE recommendation. Finally, students who were male were 1.63 times ( $\mathrm{p}=.01)$ more likely to meet the SE recommendation than female students, and older students were .98 times as likely to meet the SE recommendation, compared to their younger counterparts, holding other variables constant ( $\mathrm{p}$ $=.03)$.

\section{Discussion}

This study examined predictors of MVPA and SE at a large, northwestern public university in an effort to identify factors that may be used to design campus-specific PA interventions. The most important findings were that (a) a large percentage of survey participants from this campus were overweight/obese and/or did not meet the PA recommendations, (b) perceived health status was a significant predictor of meeting both MVPA and SE recommendations, (c) on-campus housing status was associated with a higher probability of meeting the MVPA recommendation, (d) interest in PA and knowledge about PA were positively associated with the probability of meeting the SE recommendation, (e) high overall stress level was negatively associated with the probability of meeting the SE recommendation, and (f) being a male and of younger age were significant predictors of meeting the SE recommendation.

Compared to previous studies that examined predictors of PA in college students, (Dinger, Brittain, \& Hutchinson, 2014; Sylvia Bobiak \& Caldwell, 2006), this sample was unique in that students were generally older; the mean age of the sample was 26.5 years. In comparison to a previous nationwide study of college students, a larger proportion of this sample was considered overweight or obese $(34.1 \%$ vs. $43.4 \%$, respectively) and less active (68\% vs. 52.6\% met the PA recommendations for MVPA or SE, respectively) (American College Health Association, 2011; Keating et al., 2005). The high prevalence of older overweight or obese students with high levels of physical inactivity in this population is noteworthy because this sample is different from previous studies with traditional aged college students (Dinger et al., 2014; Fountaine et al., 2011). The largest and most current study on predictors of PA in college students to date examined only aerobic activity as the outcome variable, utilized the entire NCHA data set $(n=67,861)$, and the sample was mostly female (68\%), White, between the ages of 18-20 years, with a healthy BMI (18-24.9 kg/m²) (Dinger et al., 2014).

\section{Predictors of Meeting Both MVPA and SE Recommendations}

Consistent with findings from previous studies (Kulavic et al., 2013; Nguyen-Michel, Unger, Hamilton \& Spruijt-Metz, 2006), poor perceived health status was associated with a lower probability of meeting MVPA and SE recommendations. This makes sense because if students do not feel well or do not perceive that PA will help their poor health status, encouraging them to be physically active may be difficult. Kulavic et al. (2013) compared these groups and found that compared to traditional students, non-traditional students were less likely to participate in PA due to a fear of injury, lack of skill, or a lack of resources; Dinger et al. (2014) concurred with these findings. A challenge for health professionals on college campuses is figuring out how to get those who feel less healthy to be active.

\section{Predictors of Meeting MVPA Recommendation}

Previous studies support our finding that students living on-campus participate in more MVPA (Ajibade, 2011; Small, Bailey,-Davis, Morgain, \& Maggs, 2013; Peachey \& Baller, 2015). Researchers explained that finding by acknowledging that students who live on campus have higher accessibility to PA outlets or live in safe neighborhoods that typically exist near campus (Ajibade, 2011; Small, Bailey,Davis, Morgain, \& Maggs, 2013). It is possible that different sport cultures, university size, location, student demographics, or weather explain some of these differences. The studied university has several potential areas for participating in PA, including a nearby greenbelt (i.e., bike/walking path), parks, and the student recreation center. These facilities are all 
Table 2.

Logistic Regression of Socio-demographic Characteristics and Personal Factors Predicting the Probability of Students Meeting the MVPA and SE Recommendations.

MVPA Recommendation

\begin{tabular}{|c|c|c|c|c|c|c|c|c|c|c|c|}
\hline Predictor & Comparison & $\mathrm{B}$ & S.E & $\mathrm{p}$ & OR & $95 \% \mathrm{CI}$ & $\mathrm{B}$ & S.E & $\mathrm{p}$ & OR & $95 \% \mathrm{CI}$ \\
\hline \multicolumn{12}{|l|}{ Age } \\
\hline & & -.01 & .01 & .39 & .99 & {$[.97,1.01]$} & -.03 & .01 & .03 & $.98 *$ & {$[.95,1.00]$} \\
\hline \multirow[t]{2}{*}{ Gender } & Female vs Male & & & & & & & & & & \\
\hline & & .03 & .18 & .87 & 1.03 & {$[.73,1.46]$} & .49 & .18 & .01 & $1.63^{*}$ & {$[1.15,2.32]$} \\
\hline \multirow[t]{2}{*}{ Housing } & Off-campus vs On-campus & & & & & & & & & & \\
\hline & & -.51 & .23 & .02 & $.60^{*}$ & {$[.39, .93]$} & .21 & .24 & .38 & 1.23 & {$[.77,1.97]$} \\
\hline Perceived health status & Good and Excellent Health vs Poor Health & .78 & .37 & .03 & $2.19 *$ & {$[1.07,4.50]$} & 1.03 & .40 & .01 & $2.80 *$ & {$[1.27,6.18]$} \\
\hline Knowledge about PA & Have Knowledge vs Have No Knowledge & .31 & .16 & .06 & 1.36 & {$[.99,1.87]$} & .51 & .17 & .01 & $1.66^{*}$ & {$[1.19,2.31]$} \\
\hline $\begin{array}{l}\text { Interest to Receive Inform. } \\
\text { on PA }\end{array}$ & Have Interest vs Have No Interest & .17 & .16 & .28 & 1.19 & {$[.87,1.64]$} & .40 & .17 & .02 & $1.50^{*}$ & {$[1.08,2.08]$} \\
\hline Overall Stress & & -.13 & .08 & .11 & .88 & {$[.75,1.03]$} & -.21 & .08 & .01 & $.81 *$ & {$[.69, .96]$} \\
\hline
\end{tabular}

Abbreviations: B, regression coefficient; S.E., standard error; CI, confidence interval;

Race, BMI, academic performance, type of student, perceived safety, and other factors of stress were not significant predictor of meeting both MVPA and SE recommendations. 
within walking distance of the university. Other colleges may want to carefully consider the location of their recreation facilities on campus with the knowledge that a better location often translates into increased use.

\section{Predictors of Meeting Strength Training Recommendation}

Students who were interested in receiving information about PA and had knowledge about PA were more likely to meet the SE recommendation. Also, consistent with previous studies examining predictors of PA in college students, knowledge about PA was predictive of SE (Ornes \& Ransdell, 2007; Parrott, Tennant, Olejnik, \& Poudevigne, 2008). It is possible that students perceive that $\mathrm{SE}$ requires additional time for learning technical knowledge about muscle anatomy, exercise physiology, and/or body building strategies. These findings may point to the need for college campuses to offer additional training or education (e.g., health and wellness core course) about PA to all levels of college students.

Relative to stress, only one factor - overall stress - significantly predicted whether students met the SE recommendation. Students who reported higher levels of stress participated in less SE. Even though there are no specific studies investigating how stress level is related to SE in college students, these findings concur with a previous study (Dougall, Swanson, Frame, Grimm, \& Jenney, 2011) examining predictors of PA in adults. It is likely that students with high levels of stress are experiencing competing demands for their attention (e.g., family, work, school), so their desire to participate in SE may be less than for other school or home-related demands (Dougall et al., 2011). Further, when students experience stressful events, they might not choose SE as a coping strategy. Clearly, colleges should do whatever they can to minimize stress and promote the stress-relieving properties of SE participation.

Not surprisingly, male students were more likely than female students to meet the SE recommendation. This difference may be attributed to gender-stereotypes that females tend to participate in feminine sports which highlight femininity and gracefulness (e.g., aerobics, Zumba, and group exercise) while males prefer masculine sports that include danger, strength and challenge (i.e., weight lifting, skiing, etc.) (Kilpatrick et al., 2005; Salvatore \& Marecek, 2010). It is also possible that females are less familiar with weight training equipment, with less self-efficacy, compared to their male counterparts.

To our knowledge, very few studies have examined age as a predictor of meeting SE recommendations in a college population (Egli, Bland, Melton, \& Czech, 2011; Keating et al., 2013). Younger students are more likely to meet the SE recommendation than their older counterparts. It is possible that motivation mediates the relationship between participating in SE activities and age in this study. Motivational factors (e.g., appearance, physical attractiveness, and social recognition) may decrease with increasing age (Reboussin et al., 2000). Therefore, compared to older students, younger students may engage more in SE to enhance their appearance, physical attractiveness, and/or social recognition.

\section{Recommendations for Using Data to Design PA Interventions}

To optimally use campus-specific predictors of PA in college students, colleges and universities should consider (1) increasing opportunities for using campus recreation centers, (2) developing intramural and other programs that attract underserved populations on campus, (3) increasing physical education course requirements and opportunities (and tailoring those courses to the needs/requests of the students), and (4) providing innovative health and fitness evaluation opportunities. Promotion of PA opportunities (i.e., programs or courses) should target all levels of college students, especially those who are older, under significant stress, and female. Our gender-related findings, relative to physical activity recommendations, provide some potential implications for promoting physical activity at the college level. First, universities should work with recreation centers to organize unisex and single-sex 
physical activity intervention programs on campus in an attempt to provide a variety of opportunities for PA participation. Second, in response to gender-related trends in strength exercises, instructors or educators should strive to cultivate a supportive learning environment for both genders. In addition to relying on instructors or educators to minimize genderstereotypes, they can also be lessened through efforts by students' significant others such as peers, siblings, or by appropriate multimedia messages (Horn, 2008).

\section{Limitations}

Although this study noted several interesting and novel findings, some limitations are worth mentioning. First, the survey was selfadministered and online, potentially leading to social desirability bias. Also, the validity of the PA questions may be affected by the students' knowledge about moderate and vigorous $\mathrm{PA}$ and SE. Their ability to accurately recall their PA during the past seven days may have impacted the results of this study. Also, due to the small portion of graduate students and students with different ethnicities in the sample, meaningful data analysis on PA in these sub-populations is still needed. Fourth, questions asked in the survey were limited, which hampered our ability to measure or apply some constructs. Other predictors of PA such as enjoyment of PA should be considered in the future because enjoyment of PA has been positively correlated with participation in PA in previous studies (Trost, Owen, Bauman, Sallis, \& Brown, 2002).
Finally, this sample was drawn from one single university with a large percentage of females-which may reduce the generalizability of the results to other universities.

\section{Conclusions}

These findings provide a regression model for examining campus specific predictors of PA, and they offer vital information for health professionals at universities serving a larger than normal proportion of non-traditional aged students. This information can and should be used to increase students' PA on campus. Ideally, collaborative relationships between recreation centers, university security departments, university health services and related academic departments should be developed to promote PA on campuses. Staten, Miller, Melody and Rayens (2005) suggested that colleges should promote student engagement in PA using an Ecological perspective that considers individual, interpersonal, community, and policy-related factors. For example, university recreation centers may work with academic departments to organize unisex and single-sex physical activity programs. University health services may recommend those who are older, under significant stress, and female taking recreation course in recreation centers or physical education course in academic departments.

\section{References}

Ajibade, P.B. (2011). Physical activity patterns by campus housing status among African American female college students. Journal of Black Studies, 42(4), 548-560.

American College Health Association. (2002). Health campus 2010: Make it happen. Baltimore, MD: American College Health Association.

American College Health Association. (2012). American College Health Association-National College Health Assessment II: ACHA-NCHA II reliability and validity analyses 2011. Hanover, MD: American College Health Association. Retrieved July 2, 2012, from http:// www.achancha.org/docs/ACHA-NCHA-II_UNDERGRAD_ReferenceGroup_ExecutiveSummary_ Spring2012.pdf

Asano, K., Ishimura, I., Abe, H., Nakazato, M., Nakagawa, A., \& Shimizu, E. (2015). Cognitive Behavioral therapy as the basis for preventive intervention in a sleep health program: A quasiexperimental study of e-Mail newsletters to college students. Open Journal of Medical Psychology, 4, 9-16. 
Leung, K.M., Ransdell, L.B., Gao, Y., Shimon, J., Lucas, S., Chung, P. K. / Californian Journal of Health Promotion 2016, Volume 14, Issue 1, 44-56.

Babers-Henry, M. (2015). Psychological and physical health predictors of academic achievement for African American college students (Master's thesis). Retrieved Jan 14, 2016, from http://media.proquest.com/media/pq/classic/doc/3741649361/fmt/ai/rep/NPDF?_s=WSLJDwJpG57 U5bSDWhlwyQF2Qoc\%3D

Buckworth, J., \& Nigg, C. (2004). Physical activity, exercise, and sedentary behavior in college students. Journal of American College Health, 53(1), 28-34.

Chappell, C. (2011). An interdisciplinary approach to improving student physical activity and nutrition behaviors (Master's thesis). Retrieved Jan 14, 2016, from http://digitalcommons.georgiasouthern.edu/cgi/viewcontent.cgi?article=1108\&context=etd

Craigie, A. M., Lake, A. A., Kelly, S. A., Adamson, A. J., \& Mathers, J. C. (2011). Tracking of obesityrelated behaviours from childhood to adulthood: A systematic review. Maturitas, 70(3), 266-84.

Dinger, M. K., Brittain, D. R., \& Hutchinson, S. R. (2014). Associations between physical activity and health-related factors in a national sample of college students. Journal of American College Health, 62(1), 67-74.

Dougall, A. L., Swanson, J. N., Grimm, J. R., Jenney, C. T., \& Frame, M. C. (2011). Tempering the decline in college student physical activity using informational interventions: Moderating effects of stress and stage of change. Journal of Applied Biobehavioral Research, 16(1), 16-41.

Egli, T., Bland, H. W., Melton, B. F., \& Czech, D. R. (2011). Influence of age, sex, and race on college students' exercise motivation of physical activity. Journal of American College Health, 59(5), 399406.

Fielder, C. R. (2008). Knowledge, motivations, and behaviors regarding eating a healthy diet and physical activity in relation to self-esteem in college students (unpublished bachelor's dissertation). Texas State University, San Marcos, TX.

Fountaine, C. J., Liguori, G. A., Mozumdar, A., \& Schuna, Jr, J. M. (2008). Physical activity and screen time sedentary behaviors in college students. International Journal of Exercise Science, 4(2), 102112.

Garber, C. E., Blissmer, B., Deschenes, M. R., Franklin, B. a, Lamonte, M. J., Lee, I. M., ... Swain, D.P. (2011). American College of Sports Medicine position stand. Quantity and quality of exercise for developing and maintaining cardiorespiratory, musculoskeletal, and neuromotor fitness in apparently healthy adults: guidance for prescribing exercise. Medicine and Science in Sports and Exercise, 43(7), 1334-1359.

Gruber, K. J. (2008). Social support for exercise and dietary habits among college students. Adolescence, 43(171), 557-575.

2007). Physical activity and public health: Updated recommendation for adults from the American College of Sports Medicine and the American Heart Association. Medicine \& Science in Sports \& Exercise, 39(8), 1423-1434.

Horn, T. S. (2008). Advances in sport psychology ( $3^{\text {rd }}$ ed.). Champaign, IL: Human Kinetics.

Keating, X. D., Castelli, D., \& Ayers, S. F. (2013). Association of weekly strength exercise frequency and academic performance among students at a large university in the United States. The Journal of Strength and Conditioning Research, 27(7), 1988-1993.

Keating, X. D., Guan, J., Pinero, J. C., \& Bridges, D. M. (2005). A meta-analysis of college students' physical activity behaviors. Journal of American College Health, 54(2), 116-125.

Kilpatrick, M., Herbert, E., \& Bartholomew, J. (2005). College students' motivation for physical activity: Differentiating men's and women's motives for sport participation and exercise. Journal of American College Health, 54(2), 87-94.

Kulavic, K., Hultquist, C. N., \& McLester, J. R. (2013). A comparison of motivational factors and barriers to physical activity among traditional versus nontraditional college students. Journal of American College Health, 61(2), 60-6.

Lowry, R., Galuska, D. A., Fulton, J. E., Wechsler, H., Kann, L., \& Collins, J. L. (2000). Physical activity, food choice, and weight management goals and practices among U.S. college students. American Journal of Preventive Medicine, 18(1), 18-27. 
Leung, K.M., Ransdell, L.B., Gao, Y., Shimon, J., Lucas, S., Chung, P. K. / Californian Journal of Health Promotion 2016, Volume 14, Issue 1, 44-56.

Lutz, R. S., Stults-Kolehmainen, M. A., \& Bartholomew, J. B. (2010). Exercise caution when stressed: Stages of change and the stress-exercise participation relationship. Psychology of Sport and Exercise, 11(6), 560-567.

McArthur, L. H., \& Raedeke, T. D. (2009). Race and sex differences in college student physical activity correlates. American Journal of Health Behavior, 33(1), 80-90.

Nehl, E. J., Blanchard, C. M., Kupperman, J., Sparling, P., Rhodes, R., Torbai, M. R., \& Courneya, K. S. (2008). Exploring physical activity by ethnicity and gender in college students using Social Cognitive Theory. Journal of Research in Health, Physical Education, Recreation, Sport \& Dance, 7(1), 11-17.

Nguyen-Michel, S. T., Unger, J. B., Hamilton, J., \& Spruijt-Metz, D. (2006). Association between physical activity and perceived stress/ hassles in college students. Stress and Health, 22(3), 179188.

Ornes, L., \&Ransdell, L. (2007). Web-based physical activity intervention for college-aged women. International Electronic Journal of Health Education. 10, 126-137.

Parrott, M. W., Tennant, L. K., Olejnik, S., \& Poudevigne, M. S. (2008). Theory of Planned Behavior: Implications for an email-based physical activity intervention. Psychology of Sport and Exercise, 9(4), 511-526.

Peachey, A. A., \& Baller, S. L. (2015). Perceived built environment characteristics of on-campus and offcampus neighborhoods associated with physical activity of college students. Journal of American College Health,63(5), 337-342.

Quintiliani, L. M., Bishop, H. L., Greaney, M. L., \& Whiteley, J. A. (2012). Factors across home, work, and school domains influence nutrition and physical activity behaviors of nontraditional college students. Nutrition Research, 32(10), 757-763.

Reboussin, B. A., Rejeski, W. J., Martin, K. A., Callahan, K., Dunn, A. L., King, A. C., \& Sallis, J. F. (2000). Correlates of satisfaction with body function and body appearance in middle- and older aged adults: The activity counseling trial (ACT). Psychology \& Health. 15(2), 239-254.

Reed, J. A., \& Phillips, D. A. (2005) Relationships between physical activity and the proximity of exercise facilities and home exercise equipment used by undergraduate university students. Journal of American College Health, 53(6), 285-290.

Reed, J. A., Powers, A., Greenwood, M., Smith, W., \& Underwood, R. (2011). Using “point of decision” messages to intervene on college students' eating behaviors. American Journal of Health Promotion, 25(5), 298-300.

Salvatore, J., \& Marecek, J. (2010). Gender in the gym: Evaluation concerns as barriers to women's weight lifting. Sex Roles, 63(7-8), 556-567.

Small, M., Bailey-Davis, L., Morgan, N., \& Maggs, J. (2013). Changes in eating and physical activity behaviors across seven semesters of college: living on or off campus matters. Health Education \& Behavior: the Official Publication of the Society for Public Health Education, 40(4), 435-41.

Snyder, T. D., \& Dillow, S. A. (2011). Digest of education statistics 2010 (NCES 2011-015). Washington, DC: National Center for Education Statistics, Institute of Education Sciences, U.S. Department of Education. Retrieved July 2, 2012, from https://nces.ed.gov/pubs2011/2011015.pdf

Staten, R. R., Miller, K., Melody, P. N., \& Rayens, M. K. (2005). College students’ physical activity: Application of an Ecological perspective. American Journal of Health Studies, 20(1), 58-65.

Sylvia-Bobiak, S., \& Caldwell, L. L. (2006). Factors related to physically active leisure among college students. Leisure Sciences, 28(1), 73-89.

Trost, S. G., Owen, N., Bauman, A. E., Sallis, J. F., \& Brown, W. (2002). Correlates of adults' participation in physical activity: review and update. Medicine and Science in Sports and Exercise, 34(12), 1996-2001. 
Leung, K.M., Ransdell, L.B., Gao, Y., Shimon, J., Lucas, S., Chung, P. K. / Californian Journal of Health Promotion 2016, Volume 14, Issue 1, 44-56.

Author Information

*Ka Man Leung

Email: kmleung@hkbu.edu.hk

Mailing address: Room AAB 926, 9/F, Academic and

Administration Building, Baptist University Road Campus, Hong Kong Baptist University, Hong Kong

Work phone: (852) 34118033 /fax number: (852) 34115757

* corresponding author 